\title{
Repeatability of egg size in two marine gastropods: brood order and female size do not contribute to intraspecific variation
}

\author{
Rachel Collin* \\ Smithsonian Tropical Research Institute, Box 0843-03092, Balboa, Republic of Panama \\ Address for correspondence: Smithsonian Tropical Research Institute, Unit 0948, APO AA 34002, USA
}

\begin{abstract}
Egg size has been shown to vary among females in many species of marine invertebrates and fishes. Usually, however, only a single reproductive event is measured for each female, leaving open the possibility that egg size could vary significantly among broods from the same female. Here I measured egg size from 3 to 7 broods per female from 2 calyptraeid species, Crepidula atrasolea and $C$. ustulatulina, in 2 experiments. In a preliminary experiment, females were raised from hatching under constant temperature in incubators; in a second larger experiment, they were raised under varying temperatures on the laboratory bench top. Under both conditions, there were significant differences in egg size among broods from each female, as well as significant differences among females from the bench top. Estimates of repeatability, which give an upper boundary on the heritability of a trait, were significantly reduced when among brood variation was included in the calculations, suggesting that caution should be used in interpreting among-female components of variation in studies that measure only a single brood per female. Egg size was not related to female size, and there was an effect of brood order on egg size in only C. ustulatulina from the bench top. Eggs produced in the incubators were larger than those from the bench top and they were more variable within broods, resulting in a lower repeatability of egg size from incubator animals than from bench top animals. The significant variation in egg size at all levels of the analysis suggests that such variation should be included in models of egg size evolution, and that the evolutionary dynamics of egg size may be more complicated than reflected in current models of life-history evolution.
\end{abstract}

KEY WORDS: Crepidula $\cdot$ Direct development $\cdot$ Phenotypic plasticity $\cdot$ Bet-hedging

\section{INTRODUCTION}

Egg size is a feature of great importance in the evolution of life histories and can vary widely among closely related species. Interspecific differences are common in many groups of marine invertebrates and recent molecular phylogenetic evidence has shown that a number of these differences have evolved rapidly (Collin 2004, Hart \& Podolsky 2005, Collin et al. 2007). The evolutionary processes by which these interspecific differences in egg size develop are not well understood and, like the evolutionary transformation of any feature, the key to such understanding lies in intraspecifc processes and the intraspecific variation upon which they act. Bernardo (1996) pointed out that detailed data documenting intraspecific variation in propagule size is simply not available for many organisms, and such data are especially rare for most groups of marine invertebrates (see reviews by Hadfield \& Strathmann 1996, Marshall \& Keough 2008, Moran \& McAlister 2009).

There are few published studies that are explicitly focused on intraspecific variation in egg size (usually measured as egg diameter) in marine invertebrates, but those that are available generally report significant differences among females. For example, a detailed study of egg size in 13 species of tropical echinoids discovered significant differences in egg size among 
females in each species (Lessios 1988). Phillips (2007) found that $20 \%$ of the variation in egg size and $86 \%$ of the variation in energy content in mussel eggs were due to variation among field-collected females. Collin \& Salazar (2010) found that $65 \%$ of the variation in egg size of laboratory raised slipper snails Crepidula atrasolea and C. ustulatulina was due to variation among females. Reviews of variation in vertebrate egg size also commonly find significant variation among females. For example, a review of 26 studies of bird egg volume found that an average of $70 \%$ of the intraspecific variance could be attributed to variation among females (Christians 2002). Studies demonstrating that $>50 \%$ of the variance in egg size is due to variation among females are also common in fish, reptiles and amphibians (reviewed by Christians 2002).

In all of the invertebrate studies listed above, a single spawning event was examined from each female, and only a few females were measured in many cases. Consequently, while the among female component of variation in egg size could be calculated, the within female component could at best be approximated from the residual variance, and could not be broken down into within and among brood components. If clutches vary through time, seasonally, or with maternal age or size, the within female component of variation could be higher relative to the among female component than is indicated from the results of these studies. Since the relative amounts of within and among female variance contributing to phenotypic variation can be used to calculate the repeatability of a trait, and therefore set an upper boundary on its heritability (Falconer \& Mackay 1996), it is important to obtain accurate estimates of these variance components.

Data from studies that explicitly examine variation in egg size within and among broods are not only necessary to calculate repeatability, but are also necessary to test some of the newly proposed hypotheses about differences in offspring variability between direct developers and species with planktotrophic larvae. For example, in a review of 102 marine invertebrates, Marshall \& Keough (2008) noted that direct developers that produce large propagules showed greater within species variation in offspring size than did species with planktotrophic development and small propagules. A possible explanation for this pattern was put forward by Marshall et al. (2008) who predicted that offspring of direct developers should vary less within each female and more among females, than do the offspring of planktotrophs. This is because mothers of direct developers should be better able to predict the conditions that will be experienced by their offspring that settle nearby, than mothers of planktotrophic larvae.

There are very few published studies of offspring size in marine invertebrates where both among and within female variation are reported explicitly. In a literature review of patterns in offspring size (measured as hatching size) variability in 25 marine invertebrates, Marshall et al. (2008) found that the CVs in offspring size among and within females (from a single clutch) ranged from 1.6 to 22.9 and 2.0 to 25.7 respectively, suggesting that variation at both levels is common. The small number of invertebrate species for which these values could be calculated (only 18 were from published studies) and the small sample sizes for many of them are also typical of the sparse literature on both invertebrates and nonavian vertebrates (Christians 2002).

The few cases where egg size has been examined from multiple broods from individual females in marine invertebrates generally show a reduction in egg size with brood order or over time. A study of the nudibranch Adalaria proxima from several sites around the northern UK found that egg size not only varied among sites, but also decreased with the age of the mother (Jones et al. 1996). Likewise, egg size and the number of eggs per egg mass decreased with time after the onset of reproduction in the opisthobranch Haloa japonica (Ito 1997); egg size decreased with age in the nudibranch Tenellia adspersa (Chester 1996, see his Fig. 3); and egg size and egg number decreased with age in the polychaete Capitella sp. (Qian \& Chia 1992). These are all short-lived weedy or annual species that generally reproduce for a season and then die. It was suggested in each study that the observed decreases in egg size were due to reduction in adult size resulting from limited feeding after the onset of reproduction, or the detrimental effects of aging. Similar decreases in propagule size with age have been reported for shortlived terrestrial species including the housefly (McIntyre \& Gooding 2000), a parasitic wasp (Giron \& Casas 2003), some butterflies (Fischer et al. 2003), and 8 weedy herbaceous plants (Cavers \& Steel 1984). Egg size has occasionally been reported to increase with age in arthropods (e.g. soil mites, Benton et al. 2005), but this is less common than a reduction in egg size (reviewed by Fox \& Czesak 2000). An exception to this general pattern appears in birds, which often show a slight but significant increase in egg size with age or experience (Christians 2002).

Previous studies of egg size and hatching size in species of Crepidula, a genus of protandrous, filterfeeding marine gastropods, have demonstrated significant intraspecific variation in egg size. Measurements of eggs produced in the laboratory showed that egg size varies with temperature and can vary among geographically distinct populations (Collin \& Salazar 2010). Despite the effects of these factors, more than half of the observed variation in egg size was due to variation among females. This variation did not seem to be due to female size. Since only a single brood was measured 
per female, it was not possible to examine the details of the within female variation in egg size, which is the focus of the present study. I measured egg size from multiple broods from numerous females of the same 2 species, Crepidula atrasolea and C. ustulatulina to (1) determine if there is significant variation in egg size among broods from a single female, (2) determine if there is significant variation in egg size among females when among brood variation is accounted for, (3) calculate the repeatability of egg size, and (4) determine if egg size varies with maternal size or brood order.

\section{MATERIALS AND METHODS}

Adult female Crepidula atrasolea Collin, 2000 and Crepidula ustulatulina Collin, 2002 were collected intertidally from Fort Pierce and Mote, Florida. Unrelated females, which are the progeny of this brood stock, were raised from hatching in the laboratory in $350 \mathrm{ml}$ plastic cups, under the same conditions. All animals were fed with $3.86 \times 10^{6}$ cells d $^{-1}$ of Isochrysis galbana strain $T$. iso. When each individual reached $\sim 7 \mathrm{~mm}$ in shell length, a smaller animal was placed with it to act as a male. Once the females began laying eggs, the males were removed to avoid competition for food. Eggs were collected from female C. atrasolea ranging from 9.7 to $23.3 \mathrm{~mm}$ and $C$. ustulatulina ranging from 10.10 to $18.35 \mathrm{~mm}$ in shell length.

A preliminary experiment was conducted where a small number of animals from both locations were kept in incubators in the dark at $23^{\circ} \mathrm{C}$ (following the completion of the experiment described by Collin \& Salazar 2010). In the larger main experiment, they were raised on the laboratory bench top at an average temperature of $20.1^{\circ} \mathrm{C}(\mathrm{SD}=1.47$; range over $600 \mathrm{~d}$, 15 to $30^{\circ} \mathrm{C}$ ) and $\sim 8$ to $10 \mathrm{~h}$ of fluorescent light $\mathrm{d}^{-1}$, but as little as $4 \mathrm{~h}$ on weekends. In this experiment, maternal size was measured each time a brood was collected. Only Crepidula atrasolea from Fort Pierce and C. ustulatulina from Mote were raised on the bench top as they were the most abundant and easiest to collect. The parents of the animals raised in incubators were collected in 2003, while those of the animals raised on the bench top were collected from the same locations in 2004 and 2005. Both species can live for $>2$ to $3 \mathrm{yr}$ in the laboratory and reproduce continuously. The primary source of mortality in the laboratory was desiccation, when either the animals crawled out of the seawater or insufficient water was inadvertently placed in the cups during water changes.

Females were checked twice a day for new eggs, which are fertilized by stored sperm prior to being laid by the female. Eggs are laid in groups of 15-60 and are contained in transparent stalked capsules, which are attached to the substrate and brooded between the female's neck and propodium. Within the capsules, the eggs are not surrounded by extraembryonic membranes; therefore, the egg measurements reported here are of the actual egg cell after extraction from the capsule, and do no include any membranes or extracellular coverings. Eggs are initially squashed together during their passage through the female genital papilla, but they separate rapidly. Since cleavage begins within hours of ovoposition and causes the size and shape to change, eggs need to be measured quickly. This is typical of almost all marine invertebrate eggs, where embryos change shape and become irregular immediately upon the initiation of cleavage; eggs with tough chorions that retain a regular shape often swell during development. Eggs that had not yet cleaved were collected, placed on a slide with a No. 1 coverslip supported by large 'clay feet' to ensure that pressure from the coverslip did not squash or alter the egg size or shape in any way, and photographed under a compound microscope. The goal was to photograph at least 20 eggs female ${ }^{-1}$; however, in some cases when the females were small or when cleavage had begun, 20 uncleaved eggs were not available. Prior to photographing the eggs from each female, a stage micrometer was photographed with the same magnification. Because many broods were collected after cleavage had begun, the order of the broods does not reflect every brood produced; rather, it reflects the order in which they were laid relative to each other.

Photographs were imported into the software program ImageJ (Abramoff et al. 2004). The micrometer photograph was used to calibrate the measurements, and the Shape Descriptor plug-in was used to measure the area, major and minor axes, aspect ratio (major axis/minor axis) and roundness $\left(4 \times\right.$ area $/ \pi \times$ diameter $\left.^{2}\right)$ of each egg. Eggs with a roundness of $<94$ were eliminated from the analysis because eggs elongate prior to cleavage and changes in shape can alter size estimates.

Exploratory analyses were used to examine variation in egg size for each female separately. One-way ANOVA was used to test for significant differences in egg size among broods from each female, resulting in 70 tests for Crepidula atrasolea and 60 tests for C. ustulatulina. In these tests, brood number was treated as a nominal unordered variable. I also used an REML (Restricted Maximum Likelihood) ANOVA to test for differences in egg size among females, with brood nested within female as a random effect. The variance components from this analysis were extracted using the Variability/Gage Chart option in JMP 5.1 and used to calculate the repeatability by dividing the among female variance by the total variance (Lessells \& Boag 1987, Flint et al. 2001). To compare the percentage of total variance explained by the among female compo- 
nent with other studies in which only a single brood was examined from each female, I repeated this analysis using only the first brood measured from each female.

To determine if egg size changes with brood order, I used a repeated-measures ANOVA as implemented in the MANOVA menu in JMP 5.1. This analysis used data from only the first 4 broods for which I obtained measurements from each female (data for the 5th and/ or 6 th brood were obtained from $<50 \%$ of the females). I also used an REML ANCOVA to test for an effect of brood order on egg size by treating the female identity as a random factor, and using shell length, brood order, and decimal date as covariates. The decimal date reflects the fact that the eggs were successfully collected over as few as $40 \mathrm{~d}$ for some females while it took as long as a year to obtain 4 broods for other females. For the preliminary experiment, female length was not measured and population of origin was included as a fixed factor. Animals from the 2 populations were combined for analysis of the data from the incubator experiment because no significant effect of population was observed.

\section{RESULTS}

Both species showed significant differences in egg size among females and among broods from each female. When multiple broods were included in the analysis, the majority of the variance in egg size was within females rather than among females and estimates of repeatability were much smaller than when only a single brood was used. There was no evidence of an effect of female size and only Crepidula ustulatulina showed an effect of brood order on egg size; however, brood date was significant in all but the smallest dataset.

\section{Individual females}

Crepidula atrasolea

A total of 7466 eggs were measured (Table 1) and each female produced these eggs over an average period of $222 \mathrm{~d}(\mathrm{SD}=138.8$; range 40 -614). In general, individual clutches from the same female were significantly different from each other; 10 of 12 and 55 of 58 females from the incubators and bench top respectively showed significant brood effects. The average egg diameter per brood from a single female ranged over $15 \mu \mathrm{m}(\mathrm{SD}=7.0 \mu \mathrm{m})$ on average across all females, and the average egg diameter per brood could differ by as much as $33 \mu \mathrm{m}$ across broods (i.e. $10 \%$ of the $328 \mu \mathrm{m}$ average diameter on the bench top) for a single female. This represents an average range in brood means for each female of $14 \%$ of egg volume, and a maximum range for a female of $30 \%$ egg volume between broods.

The range across the extreme eggs, i.e. the ratio of the largest to the smallest egg diameter, was larger in the incubators than on the bench top (2.12 vs. 1.34). Significant differences among broods occurred with the same frequency on the bench top dataset than in the incubator dataset (Fisher Exact Test $p>0.5$ ). The $\mathrm{CV}$ in egg size for each brood was significantly higher in the incubator ( $t$-test $\mathrm{p}<0.0001$; mean CVs within broods: bench top $=2.19$, incubator $=2.86$ ).

\section{Crepidula ustulatulina}

A total of 5587 eggs was measured (Table 1) and each female produced eggs over an average period of $217 \mathrm{~d}(\mathrm{SD}=147.5$; range $=43-797)$. Most females produced clutches that differed significantly in egg size; 13 of 16 and 42 of 43 females in the incubators and, and on average bench top respectively showed significant brood effects. The average egg diameter per brood ranged over $15 \mu \mathrm{m}(\mathrm{SD}=6.3$ ) for each female, and the average egg diameter per brood could differ by as much as $29 \mu \mathrm{m}(10 \%$ of the average diameter on the bench top) for a single female. This difference is similar to that observed in C. atrasolea. It represents an average range for a female of $14 \%$ in average egg volume per brood, and a maximum range of $33 \%$ in egg volume across broods from a single female. The ratio of the largest to the smallest egg diameter was much larger in the incubator than on the bench top (2.64 vs. 1.47). The large value in the incubator is primarily due to unusually large eggs in 3 broods.

Females from the bench top were more likely to produce broods that significantly differed in egg diameter from each other than were those raised in the incubators (Fisher Exact Test $\mathrm{p}<0.02$ ). However, the 4 clutches for which no differences were reported in the incubator were all from females with only 3 clutches and less than the average number of measured eggs. Therefore, the lack of significant differences among these clutches could have been a result of small sample sizes. The CV in egg size within broods was significantly higher in the incubator than on the bench top ( $t$-tests $\mathrm{p}<0.002$; mean CVs within broods: incubator $=3.4$, bench top $=2.4$ ).

\section{Brood, brood order, maternal size and maternal identity}

There was a significant effect of female identity in both species on the bench top (but not in the incuba- 
Table 1. Crepidula atrasolea and C. ustulatulina. Summary of broods and eggs measured on the bench top and in incubator experiments. Data are mean \pm SD (range)

\begin{tabular}{|lcccr|}
\hline Rearing conditions & $\begin{array}{c}\text { Number of } \\
\text { females }\end{array}$ & Broods measured female ${ }^{-1}$ & Eggs measured female $^{-1}$ & Egg diameter $(\mu m)$ \\
\hline $\begin{array}{l}\text { Crepidula atrasolea } \\
\text { Incubator }\end{array}$ & 12 & $3.66 \pm 0.47(3-4)$ & $76 \pm 15.3(51-99)$ & $349.3 \pm 21.3(248-528)$ \\
$\quad$ Bench top & 58 & $4.24 \pm 0.88(3-6)$ & $110 \pm 22.5(64-166)$ & $328.1 \pm 12.7(280-376)$ \\
C. ustulatulina & 16 & $3.5 \pm 0.8(2-5)$ & $69 \pm 23.5(40-131)$ & $316.8 \pm 24.8(197-519)$ \\
$\quad$ Incubator & 43 & $3.9 \pm 0.76(3-6)$ & $102 \pm 28.4(61-178)$ & $285.7 \pm 13.9(230-337)$ \\
Bench top & & & & \\
\hline
\end{tabular}

tors) when brood was nested as a random effect within female (REML ANOVA for Crepidula atrasolea bench top: $F=4.88, \mathrm{df}=57, \mathrm{p}<0.0001$; incubator: $F=0.99$, df $=13, \mathrm{p}=0.47$. C. ustulatulina bench top: $F=6.69$, df $=42$, p < 0.0001; incubator: $F=1.66, \mathrm{df}=16, \mathrm{p}=$ $0.09)$. The lack of significance in the incubator datasets is most likely due to the small sample sizes. The effects of individual broods nested within females were also significant on the bench top (Z-test: $C$. atrasolea $F=5.05, p<0.0005$; C. ustulatulina $F=4.48, \mathrm{p}<0.001$ ) and more than half of the variance in egg size in all cases occurred within females (Table 2). Repeatabilities (i.e. the proportion of the total variance that is due to the among female effect) from the bench top were 0.33 and 0.46 in $C$. atrasolea and $C$. ustulatulina respectively, and repeatabilities from the incubators were not significantly different from 0 because there was no significant among-females effect. When the bench top data were analyzed using only the first brood measured from each female, repeatability doubled, jumping to 0.71 for C. atrasolea and 0.79 for C. ustulatulina.

Repeated-measures ANOVA on the first 4 broods from each female showed that eggs were significantly larger in the incubator experiment than they were in the bench top experiment in both species (Table 1; Crepidula atrasolea: $F_{1,56}=47.9, \mathrm{p}<0.001 ;$ C . ustulatulina: $\left.F_{1,37}=72.2, \mathrm{p}<0.001\right)$. Neither species showed a significant overall effect of brood order (C. atrasolea: $\mathrm{p}>0.1$; C. ustulatulina: $\mathrm{p}>0.1$ ). There was no interaction between treatment and brood order for $C$. atrasolea ( $\mathrm{p}>0.3$ ), but $C$. ustulatulina showed a significant interaction $\left(F_{3,35}=\mathrm{p}<0.03\right)$. This appeared to be due to a slight increase in egg size with brood number for animals in the incubator, while those on the bench top showed no change (Fig. 1).

ANCOVA of egg diameter with female identity as a random effect showed no effect of female length in any of the datasets (Table 3). There was a significant effect of brood date in both datasets for Crepidula ustulat-

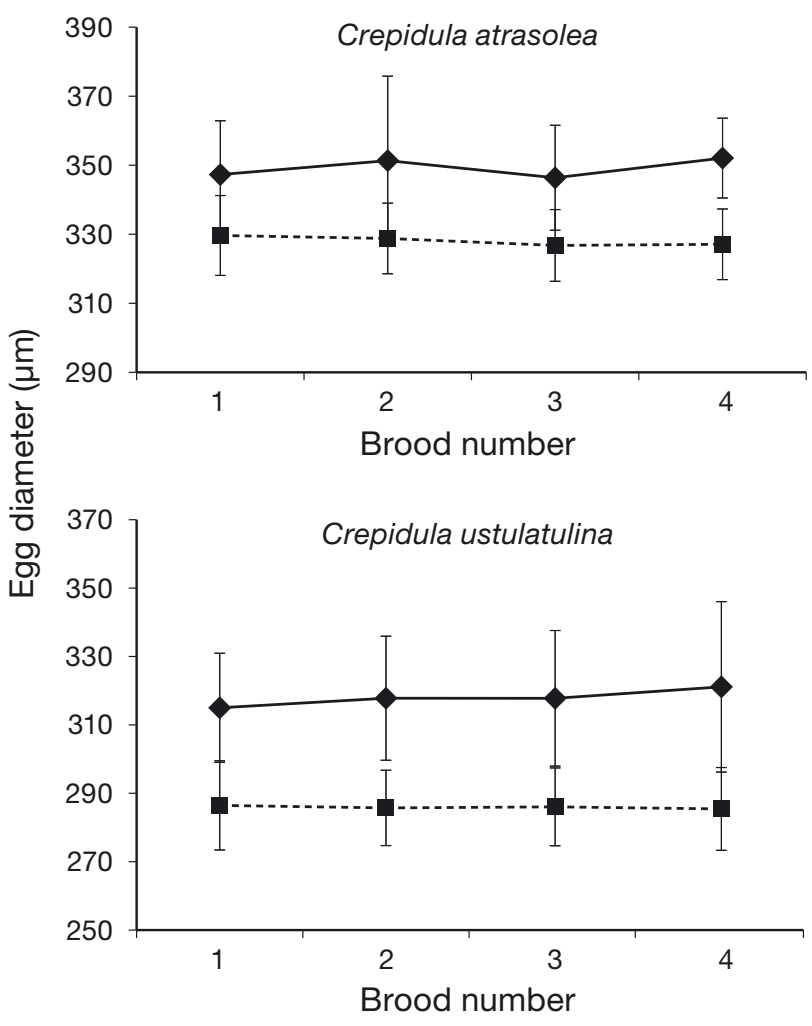

Fig. 1. Crepidula atrasolea and C. ustulatulina. Effects of brood order on egg size. Repeated-measures ANOVA showed no significant effect of brood order on egg size. Error bars: $\mathrm{SD}_{\text {; }}$ solid line: data from the incubator experiment; dashed line: data from the bench top experiment 
Table 3. Crepidula atrasolea and C. ustulatulina. REML (Restricted Maximum Likelihood) analysis of covariance test for the effects of brood order, female length and brood date on egg size for the first 4 broods in each dataset. For REML ANOVA, the estimates are shrunk towards zero, compared with the fixed-effect estimates. Bold: factors that remained significant after stepwise removal of nonsignificant variables

\begin{tabular}{|c|c|c|c|c|c|c|}
\hline \multirow[b]{2}{*}{ Factor } & \multicolumn{3}{|c|}{ Bench top -} & \multicolumn{3}{|c|}{ - Incubator - } \\
\hline & df & $F$ & $\mathrm{p}$ & df & $F$ & $\mathrm{p}$ \\
\hline \multicolumn{7}{|l|}{ C. atrasolea } \\
\hline Female (random) & 57 & $\mathrm{a}^{\mathrm{a}}$ & Shrunk & 11 & $\mathrm{~d}^{\mathrm{a}}$ & Shrunk \\
\hline Brood order & 1 & 1.34 & 0.25 & 1 & 0.00 & 0.99 \\
\hline Female length & 1 & 0.87 & 0.35 & - & - & - \\
\hline Brood date & 1 & 85.42 & $<0.0001$ & 1 & 0.86 & 0.36 \\
\hline Population & - & - & - & 1 & 1.22 & 0.27 \\
\hline \multicolumn{7}{|l|}{ C. ustulatulina } \\
\hline Female (random) & 41 &.$^{a}$ & Shrunk & 15 &.$^{\mathrm{a}}$ & Shrunk \\
\hline Brood order & 1 & 27.52 & $<0.0001$ & 1 & 0.008 & 0.93 \\
\hline Female length & 1 & 0.30 & 0.51 & - & - & - \\
\hline Brood date & 1 & 9.29 & $<0.0002$ & 1 & 37.49 & $<0.0001$ \\
\hline Population & - & - & - & 1 & 0.26 & 0.61 \\
\hline
\end{tabular}

ulina and the benchtop dataset for C. atrasolea but no effect of brood order except for the bench top dataset for C. ustulatulina. Egg size increased with brood date in C. atrasolea and C. ustulatulina from the incubator, and decreased in C. atrasolea from the bench top. For the $C$. ustulatulina dataset from the bench top, there was a significant decrease in egg size with brood number and a significant increase in egg size with brood date (Table 3).

\section{DISCUSSION}

Intraspecific variation in reproductive characteristics such as egg size is most likely ubiquitous in marine invertebrates, but few studies describe how such variation is partitioned. This study found significant variation at all levels: within a brood, among broods from the same female, and among females.

Unlike previous studies that have examined fast growing or weedy species and observed a decrease in egg size with brood order, the among brood variation observed here was not due to changes in egg size with brood order. In 3 of the datasets, among brood variation in egg size was better explained by changes in egg size with laying date. In the fourth dataset, brood order and laying date had opposite effects: a significant decrease in egg size with brood order and an increase in egg size with brood date. In total, 3 datasets showed a significant increase in egg size with brood date, and 1 showed a significant decrease with brood date. Brood date reflects maternal age, the amount of time that an individual female has been reproductive, as well as background environmental factors that may have changed during the course of the experiments. Surprisingly, only one other similar study of egg size variation in marine invertebrates has reported egg sizes that do not vary with brood order. In that study, the average egg size for 54 white shrimp was shown not to vary (1-way ANOVA) over 4 broods after ovoposition was artificially induced by eyestalk ablation (Arcos et al. 2003). However, only $15 \%$ of the animals produced 4 broods, and those that did were shown to have had larger eggs in the first brood than those that produced fewer broods, making interpretation of the data unclear. More studies are necessary to determine if the pattern of decreasing egg size with brood order or maternal age is common in perennial species or, if Crepidula atrasolea and C. ustulatulina are unusual in lacking an effect of brood order, and even sometimes showing an increase in egg size with date.

There were also significant differences in egg size among females for both species and these differences were not linked to maternal size. Egg size is often positively correlated with female size in marine invertebrates (Marshall \& Keough 2008), vertebrates (Christians 2002), arthropods (Fox \& Czesak 2000), and butterflies (GarcíaBarros 2000), although these relationships often explain less than half of the variation in egg size. There is no evidence of a relationship between female size and egg size in Crepidula atrasolea and C. ustulatulina (Collin \& Salazar 2010, this study). In Crepidula, in general, the number of egg capsules and the number of eggs per capsule increase with female size (Collin 2000b). This increase, instead of increases in egg size alone, could account for any increases in energy allocated to reproduction with increased size. In some other calyptraeids (e.g. Crepipatella dilatata), hatching size increases with female size, but this is due to increased allocation of nurse egg with female size (Chaparro et al. 1999) and not to increases in egg size.

In Crepidula atrasolea and C. ustulatulina, $\sim 30$ to $40 \%$ of the variation in egg size was attributed to variation among broods nested within females, and another 30 to $40 \%$ of the variation was attributed to variation among eggs within each brood. Therefore, more than half of the variation in egg size in all 4 datasets was due to within individual variation. Most of this variation cannot be explained by female size or brood order (see above), and since conditions in each treat- 
ment were uniform throughout the study, it is not clear what factors are responsible for this variation. Because very few studies have examined multiple broods from the same female in marine invertebrate species, it is not known if such high levels of intra-individual variation are common or exceptional.

The proportion of the total variation that is due to variation among females is referred to as the repeatability of a trait, and can be used to give a statistical upper boundary to heritability without conducting an experiment to explicitly examine heritability (Falconer \& Mackay 1996). Repeatability has been a useful measure in studies of avian reproduction where egg size has been shown to have repeatabilities that are generally $>0.5$ (Christians 2002). There has been some previous confusion in the literature about how repeatabilities should be calculated (Lessells \& Boag 1987, Flint et al. 2001) and it has been shown that reduction of data for individual eggs to brood means can result in overestimates of the among female component of the variance and therefore in an overestimate of the repeatability (Flint et al. 2001). Likewise, I have demonstrated in the case of the 2 species of Crepidula that the inclusion of multiple broods from each female significantly reduces the amount of variance in egg size that is attributed to the among female component. In fact, repeatability is more than halved when 3 or 4 broods from each female are included. Therefore, caution must be used in interpreting among female variation in studies that examined only a single brood from each female.

Despite this effect, and the high levels of among brood and within brood variation, there was significant among female variation in egg size in both Crepidula atrasolea and C. ustulatulina from the bench top when multiple broods were considered from each female. Since the bench top datasets were significantly larger than the incubator datasets in both the number of females and the number of broods per female, the estimates of repeatability from the former are more reliable. The repeatabilities and therefore the upper limits of heritability for egg size in Crepidula (0.33 and 0.46) are lower than the repeatabilities and heritabilities of egg size in birds and arthropods. Repeatability of egg size in birds is generally $>0.6$ and is higher than that of clutch size or laying date, as are the heritabilities of these same characters (Christians 2002). Studies in arthropods have shown that heritability of egg size can vary greatly with maternal diet and host as well as among populations (reviewed by Fox \& Czesak 2000, Carter et al. 2004); however, most studies of arthropods report heritabilities well above 0.4 (reviewed by Fox \& Czesak 2000, Miles et al. 2007). Finally, the only studies of heritability of egg size in marine invertebrates recovered narrow sense heritability of 0.45 and a real- ized heritability of 0.58 for the polychaete Hydroides elegans (Miles et al. 2007), and a heritability of 0.75 in the polychaete Streblospio benedicti (Levin et al. 1991). These values exceed the repeatability reported here for Crepidula egg size, and therefore suggest that egg size in Crepidula species may be less heritable than in polychaetes.

Despite the high levels of variation within and among females, environmental effects can also play a large role in intraspecific variation in egg size. In this study, we found that eggs produced in the presumably more constant environment of the incubator had both a larger size and a higher within brood CV than those produced on the bench top. Egg size is larger at lower temperatures (Collin \& Salazar 2010), but since the temperature on the bench top was cooler on average than in the incubator, differences in temperature probably cannot explain the difference in egg size between the treatments. However, the bench top temperature of $21^{\circ} \mathrm{C}$ is lower than the temperatures examined by Collin \& Salazar (2010), and a nonlinear relationship between egg size and temperature is possible. Moreover, the animals for the bench top experiment were collected and raised after the completion of the incubator experiment; therefore, other environmental factors such as the quality of the seawater or algal supply might account for the difference in egg size between the incubator and the bench top reared females, as well as differences in the pool of animals collected from the field.

Offspring are often predicted to be more variable when environmental conditions show more variation or less predictability (Koops et al. 2003, Einum \& Fleming 2004, Marshall et al. 2008). The data from this study are not consistent with this idea, as the animals in the more constant conditions of the incubators produced eggs that are more variable. However, if the conditions in the incubator are stressful, stress may have induced females to hedge their bets by producing larger and more variable eggs. Increases in egg variability have been reported to be associated with the time experienced under uniform hatchery conditions, which resulted in weight loss and presumably stress in the greenlip abalone (Graham et al. 2006). The possibility that stress may increase egg size and variability in Crepidula should be tested explicitly.

Acknowledgements. This study could not have been completed without the help of M. Salazar, M. F. Vinasco, E. Diaz and M. Lobato, who assisted in animal care. I thank R. Thacker, K. McDonald, D. Marshall, D. R. Robertson and 3 anonymous reviewers for helpful comments on the manuscript. Financial support was provided by the Smithsonian Institution's Marine Science Network, Scholarly Studies Program, and Hunterdon and Johnson Funds. This is Smithsonian Marine Station in Fort Pierce contribution \#813. 


\section{LITERATURE CITED}

Abramoff MD, Magalhaes PJ, Ram SJ (2004) Image processing with ImageJ. Biophoton Int 11:36-42

Arcos FG, Ibarra AM, Palacios E, Vazquez-Boucard C, Racotta IS (2003) Feasible predictive criteria for reproductive performance of white shrimp Litopenaeus vannamei: egg quality and female physiological condition. Aquaculture 228:335-349

Benton TG, Plaistow SJ, Beckerman AP, Lapsley CT, Littlejohns $S$ (2005) Changes in maternal investment in eggs can affect population dynamics. Proc R Soc B 272:1351-1356

Bernardo J (1996) The particular maternal effect of propagule size, especially egg size: patterns, models, quality of evidence and interpretations. Am Zool 36:216-236

> Carter MJ, Lardies MA, Nespolo RF, Bozinovic F (2004) Heritability of progeny size in a terrestrial isopod: transgenerational environmental effects on a life history trait. Heredity 93:455-459

Cavers PB, Steel MG (1984) Patterns of change in seed weight over time on individual plants. Am Nat 124:324-335

Chaparro OR, Oyarzun RF, Vergara AM, Thompson RJ (1999) Energy investment in nurse eggs and egg capsules in Crepidula dilatata Lamarck (Gastropoda, Calyptraeidae) and its influence on the hatching size of the juvenile. J Exp Mar Biol Ecol 232:261-274

Chester CM (1996) The effect of adult nutrition on the reproduction and development of the estuarine nudibranch, Tenellia adspersa (Nordmann, 1845). J Exp Mar Biol Ecol 198:113-130

Christians JK (2002) Avian egg size: variation within species and inflexibility within individuals. Biol Rev Camb Philos Soc $77: 1-26$

Collin R (2000a) Phylogeny of the Crepidula plana (Gastropoda: Calyptraeidea) cryptic species complex in North America. Can J Zool 78:1500-1514

Collin R (2000b) Sex change, reproduction and development of Crepidula adunca and C. lingulata (Gastropoda: Calyptraeidae). Veliger 43:24-33

Collin R (2002) Another last word on Crepidula convexa and a description of C. ustulatulina sp. nov. (Gastropoda: Calyptraeidae) from the Gulf of Mexico. Bull Mar Sci 70: 177-184

Collin R (2004) The loss of complex characters, phylogenetic effects, and the evolution of development in a family of marine gastropods. Evolution 58:1488-1502

Collin R, Salazar MZ (2010) Temperature-mediated plasticity and genetic differentiation in egg size and hatching size among populations of Crepidula (Calyptraeidae: Gastropoda). Biol J Linn Soc 99:489-499

Collin R, Chaparro OR, Winkler F, Veliz D (2007) Molecular phylogenetic and embryological evidence that feeding larvae have been reacquired in a marine gastropod. Biol Bull 212:83-92

Einum S, Fleming IA (2004) Environmental unpredictability and offspring size: conservative versus diversified bethedging. Evol Ecol Res 6:443-455

Falconer DS, Mackay TFC (1996) Introduction to quantitative genetics. Prentice Hall, Harlow

Fischer K, Brakefield PM and Zwaan BJ (2003.) Plasticity in butterfly egg size: why larger offspring at lower temperatures? Ecology 84:3138-3147

Editorial responsibility: Otto Kinne, Oldendorf/Luhe, Germany
Flint PL, Rockwell RF, Sedinger JS (2001) Estimating repeatability of egg size. Auk 118:500-503

Fox CW, Czesak ME (2000) Evolutionary ecology of progeny size in arthropods. Annu Rev Entomol 45:341-369

García-Barros E (2000) Body size, egg size, and their interspecific relationships with ecological and life history traits in butterflies (Lepidoptera: Papilionoidea, Hesperioidea). Biol J Linn Soc 70:251-284

Giron D, Casas J (2003) Mothers reduce egg provisioning with age. Ecol Lett 6:273-277

Graham F, Mackrill T, Davidson M, Daume S (2006) Influence of conditioning diet and spawning frequency on variation in egg diameter for greenlip abalone, Haliotis laevigata. J Shellfish Res 25:195-200

Hadfield MG, Strathmann MF (1996) Variability, flexibility and plasticity in life histories of marine invertebrates. Oceanol Acta 19:323-334

> Hart MW, Podolsky RD (2005) Mitochondrial DNA phylogeny and rates of larval evolution in Macrophiothrix brittlestars. Mol Phylogenet Evol 34:438-447

Ito K (1997) Egg-size and -number variations related to maternal size and age, and the relationship between egg size and larval characteristics in an annual marine gastropod, Haloa japonica (Opisthobranchia; Cephalaspidea). Mar Ecol Prog Ser 152:187-195

Jones HL, Todd CD, Lambert WJ (1996) Intraspecific variation in embryonic and larval traits of the dorid nudibranch mollusc Adalaria proxima (Alder and Hancock) around the northern coasts of the British Isles. J Exp Mar Biol Ecol 202:29-47

Koops MA, Hutchings JA, Adams BK (2003) Environmental predictability and the cost of imperfect information: influences on offspring size variability. Evol Ecol Res 5: $29-42$

Lessells CM, Boag PT (1987) Unrepeatable repeatabilities: a common mistake. Auk 104:116-121

Lessios HA (1988) Temporal and spatial variation in egg size of thirteen Panamanian echinoids. J Exp Mar Biol Ecol 114: $217-239$

Levin LA, Zhu J, Creed E (1991) The genetic basis of life-history characters in a polychaete exhibiting planktotrophy and lecithotrophy. Evolution 45:380-397

> Marshall DJ, Keough MJ (2007) The evolutionary ecology of offspring size in marine invertebrates. Adv Mar Biol 53: $1-60$

- Marshall DJ, Bonduriansky R, Bussiére LF (2008) Offspring size variation within broods as a bet-hedging strategy in unpredictable environments. Ecology 89:2506-2517

McIntyre GS, Gooding RH (2000) Egg size, contents, and quality: maternal-age and -size effects on house fly eggs. Can J Zool 78:1544-1551

> Miles CM, Hadfield MG, Wayne ML (2007) Heritability for egg size in the serpulid polychaete Hydroides elegans. Mar Ecol Prog Ser 340:155-162

Moran AL, McAlister JS (2009) Egg size as a life history character of marine invertebrates: Is it all it's cracked up to be? Biol Bull 216:226-242

Phillips NE (2007) High variability in egg size and energetic content among intertidal mussels. Biol Bull 212:12-19

Qian PY, Chia FS (1992) Effect of aging on reproduction in a marine polychaete Capitella sp. J Exp Mar Biol Ecol 156: $23-38$

Submitted: August 10, 2009; Accepted: April 26, 2010

Proofs received from author(s): June 20, 2010 